\section{(6) OPEN ACCESS}

'Department of General Surgery, Hopital RivieraChablais, Montreux, VD, Switzerland

${ }^{2}$ Department of Vascular Surgery, Centre Hospitalier Universitaire Vaudois, Lausanne, VD, Switzerland

\section{Correspondence to}

Dr Floryn Cherbanyk, floryn. cherban@yahoo.fr

Accepted 27 September 2016

\title{
Contained rupture of a mycotic infrarenal aortic aneurysm infected with Campylobacter fetus
}

\author{
Maria Dimitrief, ${ }^{1}$ Floryn Cherbanyk, ${ }^{1}$ Sébastien Déglise, ${ }^{2}$ Edgardo Pezzetta ${ }^{1}$
}

\section{SUMMARY \\ Mycotic abdominal aortic aneurysms (MAAAs) are rare entities accounting for $0.65-2 \%$ of aortic aneurysms. Campylobacter fetus has a tropism for vascular tissue and is a rare cause of mycotic aneurysm. We present a 73-year-old male patient with contained rupture of a MAAA caused by $C$. fetus, successfully treated with endovascular aortic repair (EVAR) and antibiotics, which is not previously described for this aetiology. Although open surgery is the gold standard, EVAR is nowadays feasible and potentially represents a durable option, especially in frail patients.}

\section{BACKGROUND}

The natural history of a mycotic abdominal aortic aneurysm (MAAA) is that of a rapid progression to rupture and usually death. ${ }^{1}{ }^{2}$ Campylobacter fetus is an actual infective agent for MAAA, especially in elderly or debilitated patients. ${ }^{3}{ }^{4}$ We report here the first case efficiently treated by endovascular aortic repair (EVAR) and antibiotic therapy. In frail patients, EVAR could be a suitable alternative, allowing immediate less invasive treatment. Even if it is generally considered a bridge therapy, it could also sometimes represent a more durable treatment option with total remission of the infection.

\section{CASE PRESENTATION}

A 73-year-old male patient presented to our emergency department after 4 days of fever, chills and pain in the lower abdomen irradiating to the back. $\mathrm{He}$ also reported having diarrhoea for 3 days. Medical history was relevant for ischaemic and hypertensive heart disease. Seven days previously he had a coronarography. He had a temperature of $37.8^{\circ} \mathrm{C}$, normal blood pressure and heart rate and abdominal pain without signs of peritonitis. No pulsatile abdominal mass was palpable.

\section{INVESTIGATIONS}

Blood tests showed an elevated white cell count of CrossMark

To cite: Dimitrief $M$, Cherbanyk F, Déglise $S$, et al. BMJ Case Rep Published online: [please include Day Month Year] doi:10.1136/bcr-2016215582
15.5 G/L (normal value: 4-10 G/L), an elevated C reactive protein of $315 \mathrm{mg} / \mathrm{L}$ (normal value $<5 \mathrm{mg} / \mathrm{L}$ ) and a haemoglobin value of $105 \mathrm{~g} / \mathrm{L}$ (normal value: 120-180 g/L). An abdominal CT scan showed a partially thrombosed infrarenal atherosclerotic aortic aneurysm of $38 \mathrm{~mm}$ with periaortitis (figure 1). A CT scan performed the next day because of worsening abdominal pain showed a contained rupture (figure 2A, B). Blood cultures were positive for C. fetus.

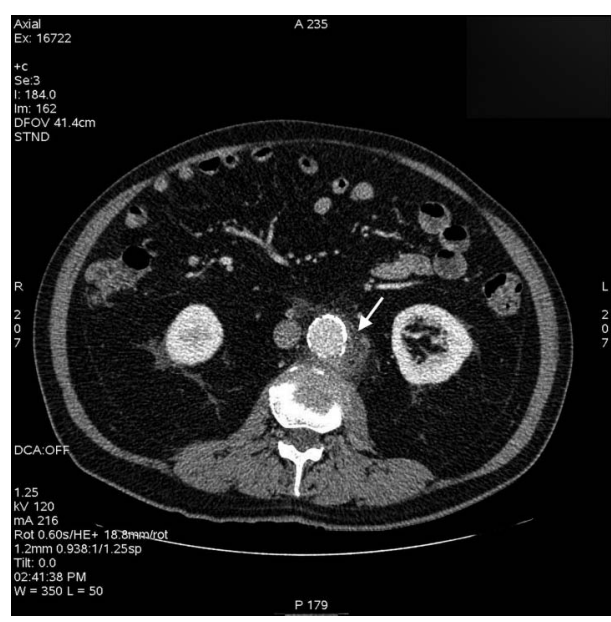

Figure 1 Abdominal CT scan showing an infrarenal atheroscleroting aortic aneurysm of $38 \mathrm{~mm}$ with periaortitis.
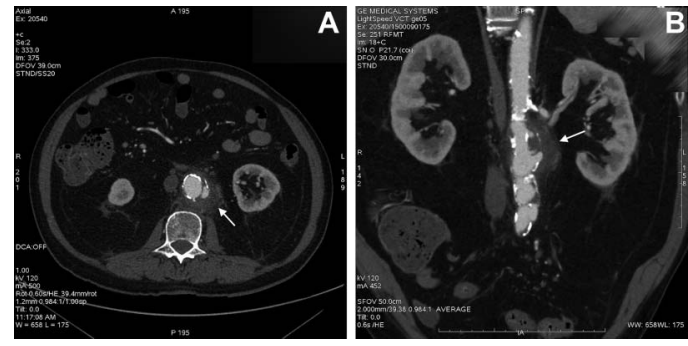

Figure 2 (A and B) CT scan performed the second day because of acute abdominal pain showing signs of contained rupture.

\section{DIFFERENTIAL DIAGNOSIS}

Contained rupture of a MAAA following infectious aortitis was the main diagnostic hypothesis. The hypothesis of a postcoronarography aneurysmal infection was invalidated by the blood cultures showing C. fetus, no cutaneous germs and by the absence of previous aneurysmal disease.

\section{TREATMENT}

Intravenous empiric antibiotic treatment with amoxicilline-clavulanate was initiated immediately after the first abdominal CT scan, and the patient was admitted to the intensive care unit. He was operated 24 hours later after clinical deterioration and a CT scan showing a contained rupture of the aneurism. He was considered unfit for open surgery because of severe ischaemic heart disease. A 'bridge therapy' with EVAR was therefore planned. $\mathrm{He}$ underwent a percutaneous endovascular aneurysmal 
Table 1 A summary of mycotic abdominal aneurysms caused by Campylobacter fetus

\begin{tabular}{|c|c|c|c|c|}
\hline Author & Year & Antibiotic therapy & Operation & Outcome \\
\hline Dolev et $a l^{6}$ & 1971 & - & Replaced-Dacron graft & Died few hours after operation \\
\hline File et $a l^{7}$ & 1979 & - & - & Died before operation \\
\hline Taylor et $a l^{8}$ & 1979 & - & - & Died before operation \\
\hline Anolik et $a l^{9}$ & 1983 & Long term & Aneurysm excision, AXBF & Alive, 45 months \\
\hline Marty et $a l^{10}$ & 1983 & 7 months & Replaced-Dacron graft & Alive, 2 years \\
\hline Blabey et $a l^{11}$ & 1983 & 7 weeks & Aneurysm excision, AXBF & Alive, 18 months \\
\hline Righter Woods ${ }^{12}$ & 1985 & 1 week & Replaced-Dacron graft & Alive, 3 years \\
\hline Perry $^{13}$ & 1985 & 8 weeks & Replaced-Dacron graft & Alive, 6 months \\
\hline Rutherford et $a l^{14}$ & 1989 & 5 months & Dacron graft & Alive, 2 years \\
\hline Jacobs et $a l^{15}$ & 1989 & - & Aneurysm excision, AXBF & Died after 7 days \\
\hline Kato et $a l^{16}$ & 1990 & 2 weeks & Aneurysm excision, AXBF & Alive, 36 months \\
\hline Allerberger et $a l^{17}$ & 1991 & - & - & Died, before operation \\
\hline Grollier et al ${ }^{18}$ & 1993 & - & Replaced-Dacron graft & ND \\
\hline Mii et $a l^{19}$ & 1998 & 3 months & Replaced-Dacron graft & Alive, 1 year \\
\hline Tran et $a l^{20}$ & 2007 & Life long & Replaced-Polyester graft & Alive, 9 months \\
\hline Cochennec et $\left.a\right|^{21}$ & 2008 & Long term & Replaced-Dacron graft & Alive, 6 months \\
\hline Cochennec et $a l^{21}$ & 2008 & Long term & Dacron graft & Alive, 5 months \\
\hline Cochennec et $a l^{21}$ & 2008 & Long term & EVAR & Died, after 2 weeks \\
\hline Cochennec et $a l^{21}$ & 2008 & Long term & Replaced-Allograft & Alive, 18 months \\
\hline Brossier et $a l^{22}$ & 2010 & - & Replaced-Dacron graft & Alive, 34 months \\
\hline Brossier et $a l^{22}$ & 2010 & - & Replaced- Silver graft & Alive, 28 months \\
\hline Brossier et $a l^{22}$ & & - & Replaced-Dacron graft & Alive, 5 months \\
\hline Brossier et $a l^{22}$ & 2010 & - & EVAR & Died, after 15 days \\
\hline Brossier et $a l^{22}$ & 2010 & - & Replaced-Allograft & Alive, 38 months \\
\hline Maeda et al ${ }^{1}$ & 2011 & - & Replaced-Polyester graft & Alive \\
\hline Maeda et al ${ }^{1}$ & 2011 & - & Replaced-Polyester graft & Alive \\
\hline Noda et $a l^{23}$ & 2011 & More than 4 weeks & Replaced-Dacron graft & Alive, 1 year \\
\hline Hagiya et $a l^{24}$ & 2013 & Long term & Replaced-Polyester J graft & Alive, 1 year \\
\hline Present case & 2015 & 6 weeks & EVAR (Endurant II stent graft) & Alive, 1 year \\
\hline
\end{tabular}

exclusion with endograft (Endurant II ETLW $16 \times 16$ C 93 and ETLW $16 \times 16$ C 82) under local anaesthesia. After blood cultures were found to be positive for C. fetus, the initial antibiotic therapy was replaced by an intravenous treatment with imipenem-cilastatin for 3 weeks followed by oral ciprofloxacin for 3 weeks.

\section{OUTCOME AND FOLLOW-UP}

Our patient had a favourable postoperative outcome. An abdominal CT scan on postoperative day 3 showed exclusion of the aneurysm by the endoprosthesis. A small type II endoleak required no specific treatment. The patient was discharged 9 days after surgery and followed up regularly. At 12 months, the clinical evolution was favourable. The clinical examination and CT scan showed no endoleak or signs of infection, so it was decided not to convert to open surgery.

\section{DISCUSSION}

The entity of mycotic aneurysm was first described by William Osler in $1885 .^{2}$ The term is, however, misleading since the majority of mycotic aneurysms are due to bacterial infection and are not fungal in nature. Since the classical triad of fever, abdominal pain and pulsatile abdominal mass is not always present, the diagnosis of a mycotic aneurysm can be very challenging and requires a high degree of suspicion. ${ }^{3} 4$ The most commonly cultured organisms include Staphylococcus (30\%), Streptococcus (10\%) and Salmonella (10\%). ${ }^{1-4}$ Other microorganisms such as Brucella can be responsible for aortitis. ${ }^{5}$ C. fetus is a very rare cause of mycotic aneurysm especially in the elderly with other underlying pathologies. ${ }^{3}$ In our case, the patient was an elderly ex-smoker with ischaemic heart disease and a recent history of gastroenteritis. He was not known for having an abdominal aortic aneurysm. During hospitalisation, he had no gastrointestinal symptoms and stool cultures that could have shown that he was an asymptomatic germ carrier were unfortunately not performed. The fact that the blood cultures were positive for C. fetus indicates that the patient had in all probability first suffered from bacteraemia with C. fetus, which led to an aortits that itself degenerated into a mycotic aneurysm. Regarding the treatment of MAAA, antibiotic therapy is essential but is inadequate if given alone. ${ }^{3}{ }^{6-9}$ The appropriate dose, duration and regimen of antibiotic therapy have not yet been established. Some authors report that a period of 4-8 weeks of antibiotic treatment is sufficient, whereas others insist on lifelong antibiotic therapy. ${ }^{13}$ There is no widely accepted consensus on this point, and the indications must therefore be determined case by case. Surgical intervention for MAAA remains challenging. Extra-anatomic bypass has been replaced ${ }^{9}$ by in situ graft replacement surgery as the gold standard treatment. ${ }^{4} 10$ EVAR has been introduced as an alternative allowing minimally invasive intervention with prompt aneurysmal exclusion and immediate control of bleeding. It is particularly useful in the case of severely ill or elderly patients. Until recently, EVAR was considered to be a temporary treatment 
prior to definitive open repair and was therefore called a "bridge to open surgery'. ${ }^{2}$ However, a recent study comparing the results of EVAR with those of conventional surgery for treatment of MAAA showed that EVAR appears to be equivalent to surgery. ${ }^{4}$ Additionally, the European multicentre collaboration trial, the largest ever on mycotic aortic aneurysm, studied the durability of EVAR by assessing late infection-related complications and long-term survival. The study concludes that EVAR can be a durable treatment option for most patients. Open repair shows short-term mortality rates of $20-40 \%$ and significant short-term and long-term morbidities related to the operation with a 5 -year survival of $35 \% .^{2}$ According to the same study, EVAR has a good short-term outcome with $91 \%$ survival at 30 days and $55 \%$ at 5 years. However, the implantation of prosthetic material in an infected site remains a major problem. The study shows $19 \%$ of fatal infection-related complications, mostly occurring during the first postoperative year for EVAR, versus only $7-10 \%$ for open surgery. Non-Salmonella-positive blood cultures seem to be the main factor associated with serious late infectious complications. ${ }^{2}$ Long-term antibiotic treatment and strict follow-up are required in order to minimise late infections that are often fatal. Our patient was successfully treated with EVAR and 6 weeks of antibiotics. At 1 year, he showed no signs of infectious complications. To the best of our knowledge, this is the 29th case of MAAA infected with C. fetus to be reported in the English literature and the first case to be successfully treated with EVAR (table 1). ${ }^{16-24}$

\section{Learning points}

- Mycotic aneurysms are rare, regardless of aetiology, and should be suspected when symptoms and patient characteristics make it an actual differential diagnosis. In such circumstances, a CT scan and blood cultures are mandatory.

- Ideal duration of antibiotic treatment has not yet been established. In our case, 6 weeks seem to have been sufficient; however, follow-up is probably too short for final conclusions.

- This case supports the use of EVAR in patients with mycotic aneurysms with Campylobacter fetus, even though earlier attempts of EVAR in similar cases failed.

Acknowledgements Dr Dominique Hennion is a radiologist in the Department of Radiology of Hôpital Cantonal de Fribourg for the CT reconstructions.

Contributors $M D$ and $F C$ were responsible for database search and writing of the article. SD performed the surgery. SD and EP were responsible for correction of the article and supervision.

Competing interests None declared.

Patient consent Obtained.
Provenance and peer review Not commissioned; externally peer reviewed.

Open Access This is an Open Access article distributed in accordance with the Creative Commons Attribution Non Commercial (CC BY-NC 4.0) license, which permits others to distribute, remix, adapt, build upon this work non-commercially, and license their derivative works on different terms, provided the original work is properly cited and the use is non-commercial. See: http://creativecommons.org/ licenses/by-nc/4.0/

\section{REFERENCES}

1 Maeda $\mathrm{H}$, Umezawa $\mathrm{H}$, Goshima M, et al. Primary infected abdominal aortic aneurysm: surgical procedures, early mortality rates, and a survey of the prevalence of infectious organisms over a 30-year period. Surg Today 2011;41:346-51.

2 Sörelius K, Mani K, Björck M, et al. Endovascular treatment of mycotic aortic aneurysms: a European multicenter study. Circulation 2014;130:2136-42.

3 Gazaigne L, Legrand P, Renaud B, et al. Campylobacter fetus bloodstreem infection: risk factors and clinical features. Eur J Clin Microbiol Infect Dis 2008;27:185-9.

4 Kan CD, Lee HL, Luo CY, et al. The efficacy of aortic stent grafts in the management of mycotic abdominal aortic aneurysm-institute case management with systemic literature comparison. Ann Vasc Surg 2010;24:433-40.

5 Casio A, De Caridi G, Lentini S, et al. Involvement of the aorta in brucellosis: the forgotten, life-threatening complication. A systematic review. Vector Borne Zoonotic Dis 2012;12:827-40.

6 Dolev E, Altmann G, Padeh B. Vibrio fetus septicemia. A case report. Isr J Med Sci 1971;7:1188-91.

7 File TM Jr, Barnishan J, Fass RJ. Campylobacter fetus sepsis with mycotic aortic aneurysm. Arch Pathol Lab Med 1979;103:143-5.

8 Taylor PR, Weinstein WM, Bryner JH. Campylobacter fetus infection in human subjects: association with raw milk. Am J Med 1979;66:779-83.

9 Anolik JR, Mildvan D, Winter JW, et al. Mycotic aortic aneurysm. A complication of Campylobacter fetus septicemia. Arch Intern Med 1983;143:609-10.

10 Marty AT, Webb TA, Stubbs KG, et al. Inflammatory abdominal aortic aneurysm infected by Campylobacter fetus. JAMA 1983;249:1190-2.

11 Blabey RG Jr, Parry MF, Bull SM, et al. Mycotic aneurysm of the abdominal aorta: successful management of Campylobacter fetus aortitis. Conn Med 1983;47:129-30

12 Righter J, Woods JM. Campylobacter and endovascular lesions. Can J Surg 1985:28:451-2

13 Perry MO. Infected aortic aneurysms. J Vasc Surg 1985;2:597-9.

14 Rutherford EJ, Eakins JW, Maxwell JG, et al. Abdominal aortic aneurysm infected with Campylobacter fetus subspecies. J Vasc Surg 1989;10:193-7.

15 Jacobs J, Van Lierde J, Nevelsteen A, et al. Campylobacter fetus subspecies fetus infection of an abdominal aneurysm. Acta Clin Belg 1989;44:123-8.

16 Kato R, Ohta T, Kazui $H$, et al. Campylobacter fetus infection of abdominal aortic aneurysm. J Cardiovasc Surg (Torino) 1990;31:756-9.

17 Allerberger F, Kasten MJ, Anhalt JP. Campylobacter fetus subspecies fetus infection. Klin Wochenschr 1991;69:813-16.

18 Grollier G, Burucoa C, Ricco JB, et al. Isolation and immunogenicity of Campylobacter fetus subsp. fetus from an abdominal aortic aneurysm. Eur J Clin Microbiol Infect Dis 1993;12:847-9.

19 Mii S, Tanaka K, Furugaki K, et al. Infected abdominal aortic aneurysm caused by Campylobacter fetus subspecies fetus: report of a case. Surg Today 1998;28:661-4

20 Tran JK, de Virgilio C. Management of an abdominal aortic aneurysm infected with Campylobacter fetus: a case report. Ann Vasc Surg 2007;21:137-42.

21 Cochennec F, Gazaigne L, Lesprit $P$, et al. Aortoiliac aneurysms infected by Campylobacter fetus. J Vasc Surg 2008:48:815-20.

22 Brossier J, Lesprit P, Marzelle J, et al. New bacteriological patterns in primary infected aorto-iliac aneurysms: a single-centre experience. Eur J Vasc Endovasc Surg 2010;40:582-8

23 Noda Y, Sawada K, Yoshida SH, et al. Mycotic abdominal aneurysm caused by Campylobacter fetus: a case report for surgical management. Ann Vasc Dis 2011:4:56-9.

24 Hagiya $\mathrm{H}$, Matsumoto $M$, Furukawa $\mathrm{H}$, et al. Mycotic abdominal aortic aneurysm caused by Campylobacter fetus: a case report and literature review. Ann Vasc Surg 2014;28:1933.e7-14. 
Copyright 2016 BMJ Publishing Group. All rights reserved. For permission to reuse any of this content visit http://group.bmj.com/group/rights-licensing/permissions.

BMJ Case Report Fellows may re-use this article for personal use and teaching without any further permission.

Become a Fellow of BMJ Case Reports today and you can:

- Submit as many cases as you like

- Enjoy fast sympathetic peer review and rapid publication of accepted articles

- Access all the published articles

- Re-use any of the published material for personal use and teaching without further permission

For information on Institutional Fellowships contact consortiasales@bmjgroup.com

Visit casereports.bmj.com for more articles like this and to become a Fellow 